\title{
Determinants of antibiotic overprescribing in respiratory tract infections in general practice
}

\author{
Annemiek E. Akkerman ${ }^{1}$, Marijke M. Kuyvenhoven ${ }^{1}$, \\ Johannes C. van der Wouden ${ }^{2}$ and Theo J. M. Verheij ${ }^{1}$ \\ ${ }^{1}$ Julius Center for Health Sciences and Primary Care, University Medical Center Utrecht, Location Stratenum, \\ PO Box 85060, 3508 AB Utrecht, The Netherlands; ${ }^{2}$ Department of General Practice, Erasmus MC-University \\ Medical Center Rotterdam, PO Box 1738, 3000 DR Rotterdam, The Netherlands
}

Received 1 June 2005; returned 5 July 2005; revised 15 July 2005; accepted 24 July 2005

\begin{abstract}
Objectives: To assess determinants of antibiotic overprescribing in patients with sinusitis, tonsillitis and bronchitis in Dutch general practice.

Patients and methods: A total of 146 general practitioners (GPs) from the Netherlands included all patients with sinusitis, tonsillitis and bronchitis during a 4 week period in the winter of 2002/2003, and recorded patient characteristics, clinical presentation and management. Overprescribing of antibiotics was assessed using the recommendations of the Dutch national guidelines as a benchmark.

Results: In almost 50\% of all 1469 respiratory tract infection (RTI) consultations (694/1469), the antibiotic prescribing decisions were in accordance with the recommendations of the Dutch national guidelines. Overprescribing was highest in tonsillitis and bronchitis $[71 \%(168 / 238)$ and $63 \%(415 / 656)$, respectively], while in sinusitis this was only $22 \%$ (128/575). Underprescribing was seen in $1 \%(3 / 238), 3 \%(17 / 656)$ and $8 \%$ (44/575), respectively. Patients who received an antibiotic prescription that was not in accordance with the guidelines had more inflammation signs such as fever (ORs 2.08, 2.18 and 3.04 , for sinusitis, tonsillitis and bronchitis, respectively), were more severely ill according to their GP (ORs $2.37,1.87$ and 1.42, respectively), and their GP assumed more often that they expected an antibiotic (ORs 1.95, 1.70 and 2.11, respectively), compared with those who did not receive an antibiotic prescription.
\end{abstract}

Conclusions: GPs overestimate symptoms and probably patients' expectations when indicating antibiotic therapy in RTI cases in daily practice. Correct interpretation of combinations of symptoms for antibiotic treatment should be emphasized, combined with adopting more patient-centred consulting skills to rationalize the prescribing of antibiotics.

Keywords: respiratory diagnoses, appropriateness, primary care, The Netherlands

\section{Introduction}

Respiratory tract infections (RTIs) are a common reason to consult a general practitioner (GP). ${ }^{1}$ Every year in the Netherlands, about 500 new cases of upper RTIs and 80 new cases of lower RTIs are presented in an average general practice. ${ }^{2}$ Treatment frequently involves the use of antibiotics, ${ }^{3}$ in spite of their questionable effectiveness in the majority of RTIs. ${ }^{4-7}$ About two-thirds of antibiotic prescriptions in Dutch general practice are for RTIs. ${ }^{8}$ Internationally, there has been much concern that antibiotics may be overused. ${ }^{9}$ Several studies have investigated determinants of antibiotic use in general practice, ${ }^{3,10-17}$ and found that patient age, ${ }^{3}$ inflammation signs (such as fever and purulent sputum ${ }^{10-12}$ ), medical knowledge of RTIs, ${ }^{17}$ diagnostic labelling ${ }^{18}$ and patient expectations ${ }^{13,19-21}$ play an important role in antibiotic prescribing decisions. However, determinants of inappropriate prescribing of antibiotics are not well investigated, even though strategies to change prescribing routines will only be successful when based on a proper understanding of why GPs prescribe antibiotics when not indicated.

Therefore, this study aimed to assess determinants of overprescribing of antibiotics in patients with sinusitis, tonsillitis and bronchitis in Dutch general practice.

*Corresponding author. Tel: +31-30-253-8396; Fax: +31-30-253-9028; E-mail: A.Akkerman-2@umcutrecht.nl 


\section{Antibiotic overprescribing in sinusitis, tonsillitis and bronchitis}

\section{Patients and methods}

\section{Setting; GPs and patients; data collection}

This study was part of a research project of which the methods were described previously. ${ }^{22}$ The 146 participating GPs included all consultations with complaints related to sinusitis, tonsillitis and bronchitis (complaints persisting up to 31 days) during a 4 week period between November 2002 and May 2003. For each consultation, GPs recorded patient characteristics, clinical presentation, their perception of the severity of illness and whether patients expected an antibiotic (Table 1). At the end of the consultation, the final diagnosis and management were recorded. Because we aimed to describe everyday practice, GPs interpreted the signs and symptoms of their patients in their usual way. Only consultations with the diagnosis codes R75 'Sinusitis', R76 'Tonsillitis' and R78 'Bronchitis', classified according to the International Classification of Primary Care (ICPC) coding, ${ }^{23}$ were included. Bronchitis in combination with asthma or chronic obstructive pulmonary disease (COPD) was excluded. Medication prescribed for these RTIs was classified according to the Anatomical Therapeutical Chemical (ATC) classification system. ${ }^{24}$ All records were checked after the 4 weeks of recording and additional information was retrieved from the patient's electronic records.

\section{Antibiotic prescribing according to Dutch national guidelines: benchmark for appropriate use}

To assess the appropriateness of prescribing antibiotics, the recommendations concerning antibiotic prescribing from the current guidelines for 'Sinusitis', 'Acute sore throat' and 'Acute cough' of the Dutch College of General Practitioners ${ }^{25-27}$ were used. The recommendations were converted into criteria and an algorithm for data analysis by three GPs with special expertise on RTIs. These criteria were used as a benchmark for appropriate use of antibiotics in sinusitis, tonsillitis and bronchitis in order to categorize the consultations with regard to antibiotic indication and antibiotic prescribing (Table 2). The categories were: antibiotics indicated and prescribed (category A), antibiotics not indicated, but prescribed (overprescribing; B), antibiotics indicated, but not prescribed (underprescribing; C), antibiotics not indicated and not prescribed (D).

\section{Analysis}

After description of the management of sinusitis, tonsillitis and bronchitis, the algorithm for appropriate prescribing of antibiotics was applied to all consultations (excluding those in which patients were referred to secondary care), using SPSS version 12.0. After checking for interactions between age and clinical determinants, we assessed the

Table 1. Determinants as recorded and used in the analyses

Used in analysis

\begin{tabular}{|c|c|c|c|c|c|}
\hline \multirow[b]{2}{*}{ Determinants } & \multirow[b]{2}{*}{ Categories } & \multirow[b]{2}{*}{ Classification } & \\
\hline & & & R75 & R76 & $\mathrm{R} 78$ \\
\hline \multicolumn{6}{|l|}{ Patient characteristics } \\
\hline age & continuous & in years & $\mathrm{X}$ & $\mathrm{X}$ & $\mathrm{X}$ \\
\hline gender & dichotomous & male (1), female (2) & $\mathrm{X}$ & $\mathrm{X}$ & $\mathrm{X}$ \\
\hline type of insurance & dichotomous & $\begin{array}{l}\text { nat. health insurance }(1) \\
\text { private insurance }(2)\end{array}$ & $\mathrm{X}$ & $X$ & $\mathrm{X}$ \\
\hline smoking & dichotomous & absent (0), present (1) & $\mathrm{X}$ & $\mathrm{X}$ & $\mathrm{X}$ \\
\hline comorbidity $^{\mathrm{a}}$ & dichotomous & absent $(0)$, present (1) & $\mathrm{X}$ & $\mathrm{X}$ & $\mathrm{X}$ \\
\hline acute rheumatic fever in history & dichotomous & absent $(0)$, present (1) & & $\mathrm{X}$ & \\
\hline \multicolumn{6}{|l|}{ Clinical presentation } \\
\hline duration of symptoms prior to consultation & continuous & in days & $\mathrm{X}$ & $\mathrm{X}$ & $\mathrm{X}$ \\
\hline $\begin{array}{l}\text { worsening clinical syndrome since } \\
\text { previous contact in same episode }\end{array}$ & dichotomous & $\begin{array}{l}\text { no worsening or no prev. } \\
\text { contact }(0) \text {, yes }(1)\end{array}$ & $\mathrm{X}$ & $\mathrm{X}$ & $\mathrm{X}$ \\
\hline cold in previous month & dichotomous & absent $(0)$, present $(1)$ & $\mathrm{X}$ & & \\
\hline peritonsillar infiltration & dichotomous & absent (0), present (1) & & $\mathrm{X}$ & \\
\hline cough & dichotomous & absent (0), present (1) & $\mathrm{X}$ & $\mathrm{X}$ & $X$ \\
\hline wheezing, dys- or tachypnoea, chest pain & dichotomous & absent (0), present (1) & & & $\mathrm{X}$ \\
\hline suspicion for pneumonia & dichotomous & absent $(0)$, present $(1)$ & & & $\mathrm{X}$ \\
\hline signs of inflammation sinus ${ }^{b}$ & continuous & number of signs $(1-2)$ & $\mathrm{X}$ & & \\
\hline signs of inflammation throat ${ }^{\mathrm{b}}$ & continuous & number of signs (1-3) & & $\mathrm{X}$ & \\
\hline signs of inflammation lower $\mathrm{RT}^{\mathrm{b}}$ & continuous & number of signs $(1-3)$ & & & $\mathrm{X}$ \\
\hline pain complaints sinus ${ }^{\mathrm{c}}$ & continuous & number of compl. (1-3) & $\mathrm{X}$ & & \\
\hline pain complaints throat ${ }^{\mathrm{c}}$ & continuous & number of compl. (1-2) & & $\mathrm{X}$ & \\
\hline \multicolumn{6}{|l|}{ GP's perception of } \\
\hline severity of illness & 4 & light (1)—severe (4) & $\mathrm{X}$ & $\mathrm{X}$ & $\mathrm{X}$ \\
\hline whether the patient expected an antibiotic & 5 & definitely not (1)—sure (5) & $\mathrm{X}$ & $\mathrm{X}$ & $X$ \\
\hline
\end{tabular}

R75, sinusitis; R76, tonsillitis; R78, bronchitis.

${ }^{a}$ Included: chronic respiratory illness, cardiovascular diseases, diabetes mellitus, atopy and malformations of ear, nose or throat.

${ }^{b}$ Inflammation signs sinus: fever or purulent nasal discharge. Inflammation signs throat: fever, inflamed pharynx or tonsillar exudate. Inflammation signs lower RT: fever, purulent sputum or auscultation abnormalities with left-right difference.

${ }^{c}$ Pain sinus: maxillary pain, pain when bending or tooth pain. Pain throat: throat ache or pain while swallowing. 


\section{Akkerman et al.}

Table 2. Criteria for antibiotic prescribing according to recommendations of the guidelines 'Sinusitis', 'Acute sore throat' and 'Acute cough' of the Dutch College of General Practitioners

\begin{tabular}{|c|c|c|c|}
\hline & Sinusitis & Acute sore throat & Acute cough \\
\hline Duration of symptoms & $>5$ days & $<14$ days & $>3$ days \\
\hline Presented symptoms & $\begin{array}{l}\text { three of the following six } \\
\text { symptoms: } \\
\text { cold in previous month, } \\
\text { purulent nasal discharge, } \\
\text { maxillary pain, } \\
\text { pain when bending, } \\
\text { tooth pain, } \\
\text { severe illness }\end{array}$ & $\begin{array}{l}\text { tonsillar exudate with } \\
\text { pain while swallowing or } \\
\text { inflamed pharynx }\end{array}$ & $\begin{array}{l}\text { sputum production or } \\
\text { auscultation abnormalities } \\
\text { with left-right difference }\end{array}$ \\
\hline $\begin{array}{l}\text { Patients at risk for } \\
\text { complications }\end{array}$ & & $\begin{array}{l}\text { presence of peritonsillar } \\
\text { infiltration, } \\
\text { severe illness, } \\
\text { acute rheumatic fever in } \\
\text { history or } \\
\text { relevant comorbidity }\end{array}$ & $\begin{array}{l}\text { age }<6 \text { months or }>75 \text { years } \\
\text { with fever, } \\
\text { heart failure or } \\
\text { suspicion for pneumonia }\end{array}$ \\
\hline
\end{tabular}

independent association (univariate and multivariate) between patient characteristics, clinical presentation and GPs' perception of severity of illness, and whether the patient expected an antibiotic on the one hand (see Table 1 for the exact determinants for analysis), and overprescribing on the other. The analyses of determinants of overprescribing addressed consultations without an indication for antibiotic treatment (categories B and D), with category B 'antibiotics not indicated, but prescribed' (overprescribing) being the outcome measure. Associations were assessed by odds ratios (ORs) with $95 \%$ confidence intervals $(95 \% \mathrm{CI})$ using logistic regression (backward stepwise analysis) with Generalised Estimating Equation estimations ${ }^{28}$ in SAS version 8.02 , to control for clustering at the level of GPs.

\section{Results}

\section{Consultations, patients and management}

The 146 GPs included 1490 consultations for sinusitis $(n=581)$, tonsillitis $(n=245)$ and bronchitis $(n=664)$ (median: eight consultations per GP; range: 1-32 consultations). Mean age of the patients was 37 years (range: 0-98 years) and 41\% were male (Table 3). Patients with a diagnosis of sinusitis were less severely ill compared with patients with tonsillitis and bronchitis. Almost half of the patients with sinusitis $(47 \%)$ had symptoms for $>2$ weeks prior to the consultation. Two-thirds of patients with tonsillitis had fever $(65 \%)$ and one-third had symptoms lasting <4 days (39\%). One-third of patients with bronchitis had comorbidity (37\%) and one-third had symptoms lasting $>2$ weeks prior to the consultation (35\%).

Antibiotics were prescribed in $80 \%(1184 / 1490)$ of the consultations with very few differences between sinusitis $(80 \%$; 467/581), tonsillitis $(81 \%$; 199/245) and bronchitis $(78 \%$; 518/664) (Table 3). In $1 \%$ of consultations $(21 / 1490)$, patients were referred to secondary care.

\section{Appropriateness of antibiotic prescribing}

In almost half of the consultations about sinusitis, tonsillitis and bronchitis the antibiotic prescribing decisions were in accordance with the recommendations of the Dutch national guidelines
$(A+D=48 \%)$ (Figure 1). In the remainder of the consultations, the antibiotic prescribing decisions were not in accordance with the guidelines $(\mathrm{B}+\mathrm{C})$; in $48 \%$ antibiotics were not indicated but prescribed (B: overprescribing), and in only $4 \%$ antibiotics were indicated but not prescribed (C: underprescribing).

These percentages varied according to the type of infection; in $70 \%$ of sinusitis consultations the antibiotic prescribing decisions were according to the recommendations, whereas in tonsillitis and bronchitis the recommendations were followed in 28 and $34 \%$ of consultations, respectively. Overprescribing was highest in tonsillitis and bronchitis (in 71 and $63 \%$ of all consultations, respectively), as opposed to $22 \%$ for sinusitis; underprescribing was highest in sinusitis (in $8 \%$ of all consultations), as opposed to $1 \%$ for tonsillitis and $3 \%$ for bronchitis (Figure 1). Thus, underprescribing was not frequent in these RTIs, and therefore not analysed.

\section{Determinants associated with antibiotic overprescribing}

Overall, patients who received an antibiotic prescription that was not in accordance with the recommendations of the Dutch national guidelines, had more inflammation signs such as fever, were more severely ill according to the GP and their GP more often assumed they expected an antibiotic, compared with those who rightly did not receive an antibiotic (Tables 4 and 5). In sinusitis cases, patients with National Health insurance and patients with cough were more likely to receive an antibiotic prescription that was not in accordance with the guideline. In bronchitis consultations, older patients and patients who were not wheezing were more likely to receive an antibiotic prescription that was not in accordance with the guideline (Tables 4 and 5). Regarding overprescribing of antibiotics, no interactions were found between age and determinants.

\section{Discussion}

In half of the consultations for sinusitis, tonsillitis and bronchitis, antibiotic prescribing decisions were in accordance with the recommendations of the Dutch national guidelines. Differences between the RTIs were considerable. Overprescribing was highest in 


\section{Antibiotic overprescribing in sinusitis, tonsillitis and bronchitis}

Table 3. Patient characteristics and management $(n=1490)$ in percentages

\begin{tabular}{|c|c|c|c|c|}
\hline \multirow[b]{2}{*}{ Patient characteristics } & \multicolumn{4}{|c|}{ Respiratory tract infections } \\
\hline & $\begin{array}{c}\text { sinusitis } \\
(n=581) \%\end{array}$ & $\begin{array}{l}\text { tonsillitis } \\
(n=245) \%\end{array}$ & $\begin{array}{l}\text { bronchitis } \\
(n=664) \%\end{array}$ & $\begin{array}{c}\text { Total } \\
(n=1490) \%\end{array}$ \\
\hline \multicolumn{5}{|l|}{ Age } \\
\hline $0-12$ years & 2 & 30 & 29 & 19 \\
\hline \multicolumn{5}{|l|}{ Gender } \\
\hline male & 36 & 41 & 46 & 41 \\
\hline \multicolumn{4}{|l|}{ Comorbidity } & 26 \\
\hline \multicolumn{5}{|l|}{ Fever } \\
\hline present & 25 & 65 & 38 & 37 \\
\hline \multicolumn{4}{|c|}{ Previous contact in same episode } & 24 \\
\hline \multicolumn{5}{|c|}{ GP perception of severity of illness } \\
\hline \multicolumn{5}{|c|}{ Duration of symptoms prior to consultation } \\
\hline $0-3$ days & 7 & 39 & 14 & 15 \\
\hline 4-5 days & 13 & 30 & 19 & 19 \\
\hline $6-13$ days & 33 & 22 & 32 & 30 \\
\hline $14+$ days & 47 & 9 & 35 & 36 \\
\hline $\begin{array}{l}\text { Management } \\
\text { antibiotic prescription }\end{array}$ & $80 \%$ & $81 \%$ & $78 \%$ & $80 \%$ \\
\hline
\end{tabular}

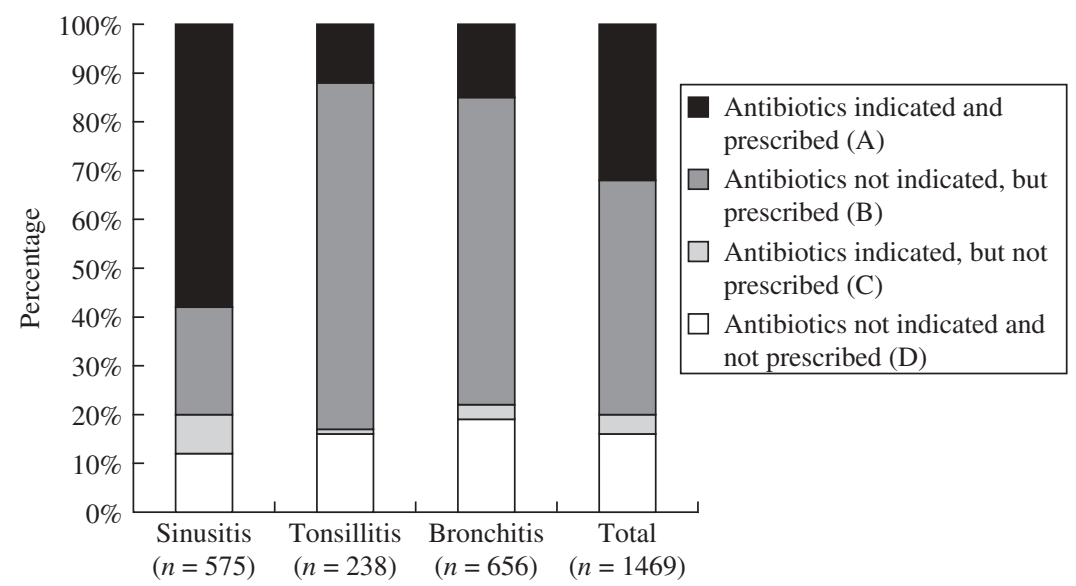

Figure 1. Appropriateness of antibiotic prescribing for respiratory tract infections $(n=1469)$.

tonsillitis and bronchitis (in 71 and in $63 \%$ of the consultations, respectively), whereas in sinusitis this was $22 \%$. Patients who received an antibiotic prescription that was not in accordance with the Dutch national guidelines, had more inflammation signs such as fever, were more severely ill according to their GP and their GP more often assumed that they expected an antibiotic, compared with those who rightly did not receive an antibiotic prescription.

\section{Strengths and weaknesses of the study}

This is a large study and characteristics of participating GPs did not differ from the average Dutch GP. ${ }^{29}$ However, all participating GPs were volunteers, which might indicate that these GPs adhere more strongly to guidelines than non-participating GPs. In that case, our results would underestimate the inappropriateness of antibiotic prescribing. It is, however, highly unlikely that a possible underestimation of inappropriate antibiotic prescribing would also affect the associations studied.

While our data can be considered complete for antibiotic prescriptions, misclassification of clinical determinants is always possible. Such misclassification because of missing data might result in inaccurate estimates of appropriateness of antibiotic prescribing. However, bias would only occur if misclassification is limited to a specific subgroup of patients; we think this is highly unlikely. 


\section{Akkerman et al.}

Table 4. Determinants of overprescribing of antibiotics for respiratory tract infections; univariate odds ratios (ORs) with $95 \%$ confidence intervals $(95 \% \mathrm{CI})$

\begin{tabular}{|c|c|c|c|}
\hline & $\begin{array}{l}\text { Sinusitis }(n=181) \\
\text { OR }(95 \% \text { CI })\end{array}$ & $\begin{array}{c}\text { Tonsillitis }(n=206) \\
\text { OR }(95 \% \mathrm{CI})\end{array}$ & $\begin{array}{c}\text { Bronchitis }(n=526) \\
\text { OR }(95 \% \mathrm{CI})\end{array}$ \\
\hline \multicolumn{4}{|l|}{ Patient characteristics } \\
\hline age & - & - & $1.01(1.00-1.02)$ \\
\hline type of insurance & $0.70(0.38-1.29)$ & - & - \\
\hline \multicolumn{4}{|l|}{ Clinical presentation } \\
\hline cough & $3.09(1.30-7.35)$ & - & - \\
\hline wheezing & NA & NA & $0.60(0.42-0.86)$ \\
\hline signs of inflammation (number) & $3.08(1.81-5.22)$ & $3.01(1.88-4.83)$ & $3.47(2.55-4.74)$ \\
\hline \multicolumn{4}{|l|}{ GP perception of } \\
\hline severity of illness & $3.05(1.87-4.99)$ & $3.23(1.81-5.77)$ & $1.68(1.34-2.12)$ \\
\hline whether patient expected an antibiotic & $1.94(1.43-2.62)$ & $2.02(1.29-3.19)$ & $2.46(1.96-3.09)$ \\
\hline
\end{tabular}

Odds ratio <1: negative association [the lower the value of the variable (see Table 1), the more overprescribing]. Odds ratio $>1$ : positive association (the higher the value of the variable, the more overprescribing).

- , Not in final model.

NA, not applicable.

Table 5. Determinants of overprescribing of antibiotics for respiratory tract infections; multivariate odds ratios (ORs) with $95 \%$ confidence intervals $(95 \% \mathrm{CI})$

$\begin{array}{ccc}\text { Sinusitis }(n=181) & \text { Tonsillitis }(n=206) & \text { Bronchitis }(n=526) \\ \text { OR }(95 \% \mathrm{CI}) & \text { OR }(95 \% \mathrm{CI}) & \text { OR }(95 \% \mathrm{CI})\end{array}$

\begin{tabular}{|c|c|c|c|}
\hline \multicolumn{4}{|l|}{ Patient characteristics } \\
\hline age & - & - & $1.01(1.00-1.02)$ \\
\hline type of insurance & $0.43(0.21-0.89)$ & - & - \\
\hline \multicolumn{4}{|l|}{ Clinical presentation } \\
\hline wheezing & NA & NA & $0.62(0.42-0.91)$ \\
\hline signs of inflammation (number) & $2.08(1.18-3.66)$ & $2.18(1.37-3.47)$ & $3.04(2.17-4.26)$ \\
\hline whether patient expected an antibiotic & $1.95(1.36-2.78)$ & $1.70(1.13-2.56)$ & $2.11(1.71-2.60)$ \\
\hline
\end{tabular}

Odds ratio <1: negative association [the lower the value of the variable (see Table 1), the more overprescribing]. Odds ratio $>1$ : positive association (the higher the value of the variable, the more overprescribing).

- , Not in final model.

NA, not applicable.

Guidelines are partly evidence-based, partly based on expert opinion, and should be regarded as the best indication at a given moment on how patients should be treated. In individual patients GPs can, of course, have good reasons to diverge from guidelines. However, taking into account the large number of patients in our study, we think non-compliance with the current guidelines is the best estimation of inappropriate antibiotic prescribing in the total group of patients under study.

\section{Comparison with the literature}

In about half of the consultations antibiotics were prescribed, while not indicated. In this respect our results support the impression of de Melker ${ }^{30}$ that about half of the antibiotic prescriptions for RTIs in Dutch general practice are unnecessary. ${ }^{30}$

In another study on acute otitis media, ${ }^{22}$ we found the same determinants of antibiotic overprescribing. Apparently these determinants (severity of illness and signs of inflammation, which are in fact mentioned in the guidelines as criteria for antibiotic treatment), were recognized by participating GPs as important items irrespective of the type of RTI, but given too much weight, which is in accordance with other studies. ${ }^{10-12}$ GPs prescribed antibiotics in the presence of one or two criteria, whereas according to the guidelines more criteria (e.g. certain duration of symptoms, inflammation signs and a risk for complications) should be present. It seems that although GPs realize which clinical signs and symptoms are relevant indications for antibiotic use, they still find it difficult to refrain from prescribing antibiotics in large subgroups of patients. For instance, the results show that in sinusitis cases patients with cough, and in bronchitis cases older patients and patients not wheezing, were more likely to receive an antibiotic prescription even though this was not in accordance with the guidelines. There are no reports that these latter patients have a higher risk of complications. Overprescribing also occurred in patients with National Health insurance. 


\section{Antibiotic overprescribing in sinusitis, tonsillitis and bronchitis}

In addition, we found that GPs' perceptions of patients' expectations play an important role in prescribing antibiotics when they are not indicated. This confirms the results of other studies reporting that GPs tend to overestimate patients' expectations on this subject. ${ }^{13,19-21}$ It is worthwhile exploring whether a patient with an RTI really expects an antibiotic, or merely desires any effective treatment ${ }^{21}$ or reassurance that nothing is seriously wrong. ${ }^{31}$

Apparently it is difficult for GPs to apply clinical criteria as described in the Dutch national guidelines in daily practice. More appropriate use of the guidelines in this field should be targeted to prevent over- and underprescribing of antibiotics. In particular, correct interpretation of combinations of signs and symptoms as indications for antibiotic therapy should be emphasized. Adopting more patient-centred consulting skills might be a tool to rationalize prescribing antibiotics ${ }^{32}$ and enhance patients' self-management, which might also decrease consultation rates for these complaints in the longer term. In order to reach these targets, a multiple educational intervention (including indications setting and communication skills training) has proven to be effective in the Netherlands. ${ }^{33}$

\section{Acknowledgements}

We thank the GPs who voluntarily participated in this study and recorded all consultations concerning sinusitis, tonsillitis and bronchitis. We acknowledge Truus Meijers for visiting the GPs, Frances Verheij and Rhea Wilken for all the administrative assistance, Peter Zuithoff for his statistical assistance, and seven medical students for extracting data from the electronic patient records in general practices. The Health Care Insurance Board (College voor Zorgverzekeringen, Diemen, the Netherlands) financed this study.

\section{References}

1. van der Linden MW, Westert GP, de Bakker DH et al. Second Dutch National Survey of General Practice. [Tweede Nationale Studie naar ziekten en verrichtingen in de huisartspraktijk: klachten en aandoeningen in de bevolking en in de huisartspraktijk.] Utrecht, Bilthoven: NIVEL, Rijksinstituut voor Volksgezondheid en Milieu, 2004.

2. van de Lisdonk EH, van den Bosch WJHM, Lagro-Janssen ALM. Morbidity in General Practice. [Ziekten in de huisartspraktijk.] Maarssen: Elsevier gezondheidszorg, 2003.

3. Akkerman $\mathrm{AE}$, van der Wouden JC, Kuyvenhoven MM et al. Antibiotic prescribing for respiratory tract infections in Dutch primary care in relation to patient age and clinical entities. J Antimicrob Chemother 2004; 54: 1116-21.

4. Williams Jr JW, Aguilar C, Cornell $\mathrm{J}$ et al. Antibiotics for acute maxillary sinusitis (Cochrane Review). In: The Cochrane Library, Issue 4, 2004. Chichester: John Wiley \& Sons, Ltd.

5. Del Mar CB, Glasziou PP, Spinks AB. Antibiotics for sore throat (Cochrane Review). In: The Cochrane Library, Issue 4, 2004. Chichester: John Wiley \& Sons, Ltd.

6. Smucny J, Fahey T, Becker L et al. Antibiotics for acute bronchitis (Cochrane Review). In: The Cochrane Library, Issue 4, 2004. Chichester: John Wiley \& Sons, Ltd.

7. Arroll B. Antibiotics for upper respiratory tract infections: an overview of Cochrane reviews. Respir Med 2005; 99: 255-61.

8. Sampers GHMA, Sturm AW. Antimicrobial agents in primary care in respiratory tract infections. [Antimicrobiële middelen in de eerste lijn bij luchtweginfecties.] Huisarts Wet 1990; 33: 220-2.

9. Jelinski S, Parfrey P, Hutchinson J. Antibiotic utilisation in community practices: guideline concurrence and prescription necessity. Pharmacoepidemiol Drug Saf 2005; 14: 319-26.
10. Gonzales R, Barrett PH Jr, Steiner JF. The relation between purulent manifestations and antibiotic treatment of upper respiratory tract infections. J Gen Intern Med 1999; 14: 151-6.

11. Murray S, Del Mar C, O'Rourke P. Predictors of an antibiotic prescription by GPs for respiratory tract infections: a pilot. Fam Pract 2000; 17: 386-8.

12. Fischer $\mathrm{T}$, Fischer $\mathrm{S}$, Kochen MM et al. Influence of patient symptoms and physical findings on general practitioners' treatment of respiratory tract infections: a direct observation study. BMC Fam Pract 2005; 6: $6-12$.

13. Dosh SA, Hickner JM, Mainous AG 3rd et al. Predictors of antibiotic prescribing for non-specific upper respiratory infections, acute bronchitis, and acute sinusitis. An Upper Peninsula Research Network study. J Fam Pract 2000; 49: 407-14.

14. de Sutter Al, de Meyere MJ, de Maeseneer JM et al. Antibiotic prescribing in acute infections of the nose or sinuses: a matter of personal habit? Fam Pract 2001; 18: 209-13.

15. Holmes WF, Macfarlane JT, Macfarlane RM et al. Symptoms, signs, and prescribing for acute lower respiratory tract illness. Br J Gen Pract 2001; 51: 177-81.

16. Coenen $S$, Michiels $B$, van Royen $P$ et al. Antibiotics for coughing in general practice: a questionnaire study to quantify and condense the reasons for prescribing. BMC Fam Pract 2002; 3: 16-25.

17. Akkerman AE, Kuyvenhoven MM, van der Wouden JC et al. Prescribing antibiotics for respiratory tract infections by GPs: management and prescriber characteristics. Br J Gen Pract 2005; 55: 114-8.

18. Hutchinson JM, Jelinski S, Hefferton D et al. Role of diagnostic labeling in antibiotic prescription. Can Fam Physician 2001; 47: 1217-24.

19. Cockburn J, Pit S. Prescribing behaviour in clinical practice: patients' expectations and doctors' perceptions of patients' expectations-a questionnaire study. BMJ 1997; 315: 520-3.

20. Macfarlane J, Holmes W, Macfarlane R et al. Influence of patients' expectations on antibiotic management of acute lower respiratory tract illness in general practice: questionnaire study. BMJ 1997; 315: 1211-4.

21. Hong JS, Philbrick JT, Schorling JB. Treatment of upper respiratory infections: do patients really want antibiotics? Am J Med 1999; 107: 511-5.

22. Akkerman AE, Kuyvenhoven MM, van der Wouden JC et al. Analysis of under- and overprescribing of antibiotics in acute otitis media in general practice. J Antimicrob Chemother 2005; doi:10.1093/jac/dki257 [published online 20 July 2005].

23. Anonymous. ICPC-2: International Classification of Primary Care. Oxford: World Organization of National Colleges, Academies, and Academic Associations of General Practitioners/Family Physicians, 1998.

24. WHO Collaborating Centre for Drug Statistics Methodology. Anatomical Therapeutic Chemical classification. http:// www.whocc.no/atcddd/ > complete ATC index 2005 (30 May 2005, date last accessed).

25. de Bock GH, van Duijn NP, Dagnelie CF et al. The practice guideline 'Sinusitis' from the Dutch College of General Practitioners [NHGstandaard Sinusitis.] Huisarts Wet 1993; 36: 255-7.

26. Dagnelie CF, Zwart S, Balder FA et al. The practice guideline 'Acute sore throat' from the Dutch College of General Practitioners. [NHGstandaard Acute keelpijn.] Huisarts Wet 1999; 42: 271-8.

27. Verheij TJM, Salomé PL, Bindels PJ et al. The practice guideline 'Acute cough' from the Dutch College of General Practitioners [NHG-standaard Acuut hoesten.] Huisarts Wet 2003; 46: 496-506.

28. Zeger SL, Liang KY. Longitudinal data analysis for discrete and continuous outcomes. Biometrics 1986; 42: 121-30.

29. Nederlands instituut voor onderzoek van de gezondheidszorg (NIVEL). www.nivel.nl > general practitioner > figures from registration. 


\section{Akkerman et al.}

[Huisarts > Aanbod: cijfers uit de registratie van huisartsen] (30 May 2005, date last accessed).

30. De Melker RA. Efficacy of antibiotics in frequently occurring airway infections in family practice. [Effectiviteit van antibiotica bij veel voorkomende luchtweginfecties in de huisartspraktijk.] Ned Tijdschr Geneeskd 1998; 142: 452-6.

31. Welschen I, Kuyvenhoven M, Hoes A et al. Antibiotics for acute respiratory tract symptoms: patients' expectations,
GPs' management and patient satisfaction. Fam Pract 2004; 21: 234-7.

32. Gonzales R, Corbett K. The culture of antibiotics. Am J Med 1999; 107: 525-6.

33. Welschen I, Kuyvenhoven MM, Hoes AW et al. Effectiveness of a multiple intervention to reduce antibiotic prescribing for respiratory tract symptoms in primary care: randomised controlled trial. BMJ 2004: 329: $431-5$. 